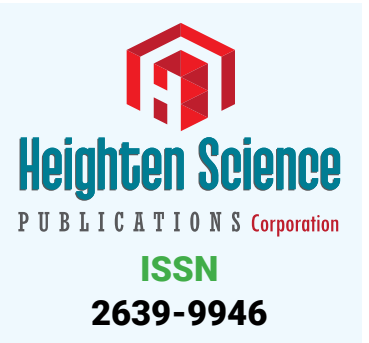

*Address for Correspondence: Dr. Mário Augusto Paschoal, Pontifical Catholic University of Campinas, São Paulo-Brazil, Email: fisioni@puc-campinas.edu.br

Submitted: 26 April 2017

Approved: 22 May 2017

Published: 22 May 2017

Copyright: @2017 Paschoal MA. This is an open access article distributed under the Creative Commons Attribution License, which permits unrestricted use, distribution, and reproduction in any medium, provided the original work is properly cited

Keywords: Child obesity; Autonomic nervous system; Heart rate; Cardiovascular system

D) Check for updates
Short Communication

\section{Cardiac Autonomic Modulation in children and Preadolescents obese}

\author{
Mário Augusto Paschoal* \\ Leader of Research Group in Cardiac Autonomic Function and Physical Activity in Health and \\ Disease, Brazil
}

\section{ABSTRACT}

Alterations in cardiac autonomic modulation of children and obese preadolescents have attracted the attention of researchers around the world. These alterations cause disorders in the cardiac autonomic control and can interfere in cardiac output and in the homeostatic actions that depends on the cardiovascular system action.

Despite several attempts, proposals or prevention programs, the control of obesity in childhood and adolescence remains a major challenge for the world today [1].

There are several metabolic disorders resulting from obesity in childhood and adolescence that lead to a survival with major limitations. In addition, one more important alteration of the health of these individuals has been studied. This is the occurrence of cardiac dysautonomia or cardiac vagus-sympathetic unbalance.

To understand this problem, firstly we need to know that the sinoatrial node, responsible for generating electrical impulses that will turn into myocardial contraction is influenced by the autonomic nervous system. The sympathetic nerves of the autonomic nervous system increase the blood pressure and heart rate (HR) and the parasympathetic nerves reduce the blood pressure and HR. So, the heart beats are adjusted, each moment, to the metabolic necessities. However, when dysautonomia exists, the HR and blood pressure can be altered and these alterations can be detected in the resting condition or during cardiac autonomic functional tests.

The problem of the cardiac dysautonomia is that there is a significant association between it and increased mortality, including death by cardiac arrest, and there is evidence of a propensity for lethal arrhythmias and increased cardiac sympathetic modulation.

Among the recent ways of cardiac autonomic modulation assessment, the more valuable tool of investigation is the heart rate variability (HRV) analysis [2,3], that is used in various areas of investigation, including in studies involving childhood obesity [4-10].

In this context, some of the first studies using HRV for evaluation of obese children and preadolescents, showed an abnormal increase in resting HR values [4-6], which was confirmed in others studies developed by Paschoal et al. [7], Altuncu et al. [8], Birch et al. [9] and Baum et al. [10].

Likewise, the analysis of HRV made from short [7] or long recordings [6,11], despite some differences, revealed reduced parasympathetic modulation represented 
by the decrease in the values of rMSSD and pNN50 indexes of time domain, and in the power HF (parasympathetic index of HRV frequency domain) when compared to their controls [12].

Eyre et al. [12] also revealed that $54 \%$ of the studies consulted by them showed increased of LF/HF ratio of HRV frequency domain, suggesting increased cardiac sympathetic modulation.

One of the major causes of HRV changes in obese children and pre-adolescents is the elevation of blood pressure presented by many of them. This hemodynamic characteristic may itself be an independent cause of the cardiac autonomic dysfunction observed in this population [13], because there is a direct association between high arterial blood pressure levels and impairment of cardiac autonomic modulation [14].

Some studies $[7,15]$ have suggested that the increase in the cardiac sympathetic activity observed in the analysis of HRV in obese children and pre-adolescents is due the activation of mechanisms related to increase cardiac output. This occur because in general, children and adult obesity is known to increase amounts of adipose tissue and lean mass through the body, and subsequently increase blood flow demand. Therefore, the heart must work harder to pump the extra blood out to the rest of the body.

Another cause of cardiac autonomic modulation dysfunction in obese children revealed by the HRV analysis, was documented by Liao et al. [15]. In their study, they say: "alterations in the morphology of the heart due to obesity could be a predictor for the dysfunction of cardiac autonomic modulation (CAM)". However, for Nagai and Moritani [5] a causal relationship between alterations in autonomic nervous system and obesity cannot be confirmed, but they suggest that a reduction in autonomic activity may be an etiological factor in the onset and development of obesity.

The relevance of these findings is that the cardiac dysautonomia contribute to the initiation and development of various cardiovascular complications of obesity in obese children and obese preadolescents [16], with these people being taxed as "children with adult hearts" [17], because they suffer decrease in their survival and life expectancy. For example, studies with application of standardized autonomic function tests involving obese pre-adolescents and morbidly obese, as the active postural maneuver, carried out by our group [18,19], failed to show differences in autonomic adjustments between obese and healthy. However, when the obese pre-adolescents remained in the standing position, after stay in supine position without moving for five minutes, they showed increased sympathetic modulation than control group [7].

Also, the physical capacity assessment with incremental protocol, from rest to anaerobic threshold (AT) showed that obese pre-adolescent and morbidly obese, reached, respectively, $42.1 \%$ and $33.4 \%$ of the distance achieved by healthy controls [20]. Likewise, the control group reached a speed at the AT, 39.6\% higher than achieved by obese, and $43.3 \%$ higher than morbid obese pre-adolescent.

Therefore, the results shown above reveal that obesity significantly limited the physical performance, not only by body weight, but also by cardiac dysautonomia because this problem also causes limitations in the autonomic cardiac adjustment during physical effort.

Through this brief communication, it can be concluded that obesity in childhood and preadolescence interferes in the autonomic modulation of the heart, causing disturbances in essential adjustments to organic homeostasis at rest, in some functional autonomic tests and during aerobic exercise. Therefore, it is suggested that assessment of cardiac autonomic control by HRV must be included in the usual evaluation of these individuals in addition to the normal procedures, so that the cardiac autonomic changes can be detected and treated early. 


\section{REFERENCES}

1. World Health Organization, 2010. Global Recommendation on Physical Activity for Health. World Health Organization. Geneva.

2. Stein $\mathrm{PK}$, Bosner MS, Kleiger RE, Conger BM. Heart rate variability: a measure of cardiac autonomic tone. Am Heart J. 1994; 127: 1376-1381. Ref.: https://goo.gl/fOTKLc

3. Heart rate variability: standards of measurement, physiological interpretation and clinical use. Task Force of the European Society of Cardiology and the North American Society of Pacing and Electrophysiology. Circulation. 1996; 93: 1043-1065. Ref.: https://goo.gl/gJeKKW

4. Martini G, Riva P, Rabbia F, Molini V, Ferrero GB, et al. Heart rate variability in childhood obesity. Clin Auton Res. 2001; 11: 87-91. Ref.: https://goo.gl/401FcT

5. Nagai $\mathrm{N}$, Matsumoto $\mathrm{T}$, Kita $\mathrm{H}$, Moritani $\mathrm{T}$. Autonomic nervous system activity and the state and development of obesity in Japanese school children. Obes Res. 2003; 11: 25-32. Ref.: https://goo.gl/HKOvD5

6. Rabbia F, Silke B, Conterno A, Grosso T, De Vito B, et al. Assessment of cardiac autonomic modulation during adolescent obesity. Obes Res. 2003; 11: 541-548. Ref.: https://goo.gl/fQ12io

7. Paschoal MA, Trevizan PF, Scodeler NF. Heart rate variability, blood lipids and physical capacity of obese and non-obese children. Arq Bras Cardiol. 2009; 93: 239-246. Ref.: https://goo.gl/zXhU83

8. Autuncu ME, Baspinar $\mathrm{O}$, Keskin $\mathrm{M}$. The use of short term analysis of heart rate variability to assess autonomic function in obese children and its relationship with metabolic syndrome. Cardiol J. 2012 19: 501-506. Ref.: https://goo.gl/Mqlih

9. Birch SL, Duncan MJ, Franklin C. Overweight and reduced heart rate variability in British children: an exploratory study. Prev Med. 2012; 55: 430-432. Ref.: https://goo.gl/xdjj67

10. Baum P, Petroff D, Classen J, Kiess W, Blüher S. Dysfunction of autonomic nervous system in childhood obesity: a cross-sectional study. PloS One. 2013; 8. Ref.: https://goo.gl/kUb50e

11. Faulkner MS, Hathaway D, Tolley B. Cardiovascular autonomic function in healthy adolescents. Heart Lung. 2003; 32: 10-22. Ref.: https://goo.gl/Zy7wAa

12. Eyre ELJ, Duncan MJ, Birch SL, Fisher JP. The influence of age and weight status on cardiac autonomic control in healthy children: A review. Autonomic Neuroscience. 2014; 186: 8-21. Ref.: https://goo.gl/OrcgZY

13. Riva P, Martini G, Rabbia F, Milan A, Paglieri C, et al. Obesity and autonomic function in adolescence. Clin Exp Hypertens. 2001; 23: 57-67. Ref.: https://goo.gl/XSDjSk

14. Esler M, Straznicky N, Eikelis N, Masuo K, Lambert G, et al. Mechanisms of sympathetic activation in obesity-related hypertension. Hypertension. 2006; 48: 787-796. Ref.: https://goo.gl/Hw4Yqm

15. Liao D, Rodríguez-Colón SM, He F, Bixler EO. Childhood obesity and autonomic dysfunction: risk for cardiac morbidity and mortality. Curr Treat Options Cardiovasc Med. 2014; 16: 342. Ref.: https://goo.gl//6ncw4

16. Ito $\mathrm{H}$, Ohshima A, Tsuzuki M, Otho N, Yanagawa M, et al. Effects of increase physical activity and mild calorie restriction on heart rate variability in obese women. Jpn Heart J. 2001; 42: 459-469. Ref.: https://goo.gl/H5iXdl

17. Giuliano ICB, Caramelli B, Duncan BB, Pellanda LC. Children with adult hearts. Arq Bras Cardiol. 2009; 93:197-198. Ref.: https://goo.gl/sF0zMW

18. Ancona MC, Scodeler NF, Guidi RM, Paschoal MA. Variabilidade da frequência cardíaca em crianças eutróficas e obesas nas posições supina e bípede. Rev Ciênc Méd. 2009; 18: 69-79.

19. Paschoal MA, Pereira MC. Modulação autonômica cardíaca nas posições supina e bípede em crianças não obesas, obesas e obesas mórbidas. Rev Ciênc Méd. 2010; 19: 33-41.

20. Paschoal MA, Fontana CC. Method of heart rate variability threshold applied in obese and nonobese pré-adolescents. Arq Bras Cardiol. 2011; 96: 450-456. Ref.: https://goo.gl/FfZrul 